\title{
Treatment of actinic keratoses and cancerization field of the face and scalp with $0.015 \%$ ingenol mebutate gel in Brazilian individuals: safety, tolerability and patients' perspectives ${ }^{*}$
}

\author{
Luiz Gameiro', Luis Fernando Requejo Tovo², José Antonio Sanches Júnior ${ }^{3}$, Ivan Aprahamian ${ }^{1}$
}

DOI: http:/ / dx.doi.org/10.1590/abd1806-4841.20197938

\begin{abstract}
BACKGROUND: Actinic keratosis (AK) represents a risk of progression to squamous cell carcinoma. Ingenol mebutate gel is a novel therapeutic option for field-directed treatment.

Овлестіves: To evaluate the safety, tolerability and patients' perspectives, related to the therapeutic success of managing AKs on the face and scalp with ingenol mebutate gel in Brazilian individuals.

Methods: This was an observational, retrospective and descriptive study of 68 areas of actinic keratosis on the face and scalp treated with Ingenol mebutate gel involving a total of 37 patients. The drug was applied for three consecutive days on an area of of $25 \mathrm{~cm}^{2}$ and documentation was performed on baseline and days 4, 8, 15, 60 and 180. On day 4, the composite local skin reaction score was calculated. At the end, a questionnaire was applied to evaluate patients' perspectives about the treatment. RESULTS: Adherence was $100 \%$, no serious adverse events were recorded and the mean composite local skin reaction score (standard deviation) was $8.61 \pm 4.22$. The treatment was considered optimum by $75.68 \%$ of the patients.

STUDY LimitATIONS: Calculation of composite local skin reaction score performed only on the fourth day.

Conclusions: Treatment with ingenol mebutate gel was considered safe and tolerable in Brazilian subjects. Patients had a maximum adherence rate and a great improvement in self-esteem. The results of this research reproduce the findings of the literature.
\end{abstract}

Keywords: Keratosis, actinic; Face; Medication adherence; Patient compliance; Precancerous conditions; Skin neoplasms

\section{INTRODUCTION}

Actinic keratosis (AK), or solar keratosis, is an intraepidermal neoplasia induced by chronic exposure of the skin to ultraviolet radiation..$^{1-3}$ Considered the third most frequent disease in dermatologic consultations in the United States (US) and the fourth in Brazil, it represents the number one dermatosis in the elderly. ${ }^{4,5}$ Its prevalence is variable, ranging between $11 \%$ and $25 \%$ in northern hemisphere countries, while in Australia it is between 40 and $60 \%{ }^{6}$ In the US, it has been estimated that 58 million individuals have AK, resulting in more than one billion of dollars in treatment costs. ${ }^{7}$ Epidemiological studies in our country report a ratio between 2.9 to $13.4 \%$ in prevalence, according to population and geographic area. ${ }^{3,5,8}$ It is a major public health problem due to the cumulative risk of evolution to invasive squamous cell carcinoma (ranging from $0.6 \%$ in the first year up to $10 \%$ in the period of 10 years) and its associated potential morbimortality. ${ }^{6,9-14}$ It is important to note that: (i) up to $60 \%$ of squamous cell carcinomas (SCCs) are originated from an AK and (ii) AK diagnosis is found on perilesional sun damaged skin of $97 \%$ of SCCs. ${ }^{13,15}$ Clinically, AKs are slightly rough, erythematous or pigmented lesions, 2 to $10 \mathrm{~mm}$ in diameter, eventually hyperkeratotic, with few symptoms, in chronically sun exposed skin. Middle-aged adults and elderly are more commonly affected, mostly those with fair skin (Fitzpatrick's classification I-III) and male predominance. ${ }^{3,14,16} \mathrm{AK}$ is highly prevalent in immunosuppressed patients. ${ }^{3,17}$

\footnotetext{
Received 06 December 2017

Accepted 25 March 2018.

* Work performed at the Faculdade de Medicina de Jundiaí, Jundiaí (SP), Brazil.

Financial support: None.

Conflict of Interest: Three of the authors received honorarium from LEO Pharma. One as a speaker (Luiz Alberto Gameiro Jr) and the other two as Board consultants (Luís Fernando Requejo Tovo e José Antonio Sanches Jr).

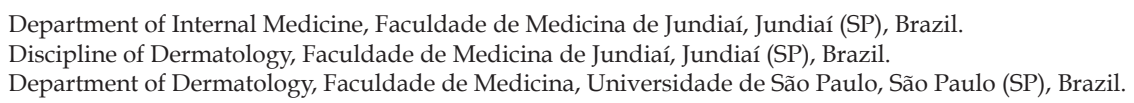


In terms of treatment, two modalities can be used to treat AKs: (i) direct destruction of the lesion (cryotherapy, shaving, curettage and eletrocoagulation, laser) and (ii) cancerization field treatment (5-fluorouracil (5-FU), imiquimod, diclofenac gel, photodynamic therapy, ingenol mebutate).${ }^{15}$ The need to include the field-directed approach is recommended by guidelines of some countries when the number of of contiguous lesions is greater than two or three in a $25 \mathrm{~cm}^{2}$ area. ${ }^{17-21}$ This is supported by the concept that subclinical dysplastic lesions are present in the circumjacent area chronically sun exposed and has the potential to progress to invasive SCC. ${ }^{16-18}$

Among efficacious treatment options in the literature for AK and field cancerization, ingenol mebutate (IM) gel is a novel agent, approved in 2012 by the Food and Drug Administration and European Medicines Agency. ${ }^{10}$ Since March 2016, it has been available in the Brazilian market. ${ }^{22}$ It consists of a macrocyclic diterpene ester derived from the Euphorbia peplus plant sap, with a dual mechanism of action: (i) direct and fast cell necrosis due to mitochondrial membrane rupture of proliferating keratinocytes and (ii) neutrophil and antibody-dependent specific cellular cytotoxicity, a process that might eliminate remaining eventually dysplastic keratinocytes. ${ }^{7,23-26}$ It is recommended to be applied on a $25 \mathrm{~cm}^{2}$ skin area once a day for two consecutive days on lesions on the trunk or extremities $(0.05 \%$ gel) and once a day for three consecutive days for those on the face and scalp $(0.015 \%$ gel). The efficacy for AKs on the face, scalp, trunk and extremities is confirmed by four randomized placebo-controlled trials. ${ }^{27}$ Treatment duration is much shorter (2-3 days) in comparison to treatments recommended for weeks to months such as imiquimod, 5-FU and diclofenac. ${ }^{27}$ For that reason, patient adherence to this new therapeutic option tends to be higher. ${ }^{10,20}$ Long term (12 months) tolerability and safety of ingenol mebutate for the treatment of AKs have been evaluated in four phase 3 studies. ${ }^{27-29}$ In Brazil, 100 patients have been evaluated in a randomized trial comparing the $0.015 \%$ ingenol gel $(n=50)$ with 5 -FU cream $(n=50) .{ }^{30}$ Ingenol gel was considered safe in facial lesions and both the duration and local skin reactions in this group were shorter. ${ }^{30}$ Midand long-term follow-up studies in Brazilian and Latin American patients have not been performed yet, neither observational ones including larger number of cases and other body sites treated, such as the scalp, for instance.

The purpose of this study was to evaluate the safety, tolerability and patients' perspectives, related to the therapeutic success of managing AKs on the face and scalp with ingenol mebutate gel in Brazilian individuals.

\section{METHODS}

\section{Participants and Study Design}

A retrospective, descriptive, observational study was performed in 68 areas of AKs on the face and scalp (grade mild to moderate) treated with ingenol mebutate (IM) including a total of 37 patients. This research involved individuals attending an outpatient dermatologic clinic, participants of a study on skin disease in the elderly, at the municipality of Jundiaí, São Paulo, in the period of July 2016 to May 2017. The following variables were considered: sex, age, race, skin type according to Fitzpatrick's classification, per- sonal history of skin cancer, previous treatments for actinic keratosis, anatomic area treated and estimated number of lesions per 25 $\mathrm{cm}^{2}$ field. Exclusion criteria were: women of childbearing age without an efficacious contraceptive method, suspicion of a basal cell or squamous cell carcinoma less than $10 \mathrm{~cm}$ distance of the target area, hyperkeratotic or cryotherapy-resistant lesions (more than two sessions) on the target area, patients on corticosteroids, immunomodulators, retinoids, keratolytic agents, immunosuppressors, chemotherapy, ultraviolet B phototherapy, or other available options for the approach of actinic keratosis.

\section{Procedures}

The treatment of all patients followed a standard procedure. A medical history and a complete skin examination (whole body skin examination), including inspection of the scalp and palmo-plantar area. After (i) clinical and dermoscopic diagnosis of at least three AKs on a target area of the face or scalp $\left(25 \mathrm{~cm}^{2}\right)$, (ii) characterization of the cancerization field (visible photodamage surrounding AKs) and (iii) absence of clinical conditions that could interfere with ingenol mebutate evaluation, the treatment of $0.015 \%$ ingenol mebutate gel was proposed. After the decision to initiate this pharmacological approach, the patient was informed about dosage (once daily application for three consecutive days) and possible local skin reactions (LSR) due to the treatment, and a didactic and illustrative handout about the LSRs was delivered. The importance of the daily use of a SPF 50+ was emphasized, as well as the recommendation of photoprotection clothing, hats and sunglasses. LSRs were divided in six clinical parameters: erythema, flaking or scaling, crusting, swelling, vesiculation or pustulation, erosion or ulceration. The severity of each of these reactions was measured by a grading scale from zero (no reaction) to four (more severe), according to the intensity of the reaction. The composite LSR score was obtained by the sum of the six individual scores, with a maximum score of 24. A photographic record of the target area was routinely performed on the first day of drug application (baseline). Two other applications, on the two following days, were performed at patient's home, by a relative or caregiver, as previously oriented by the dermatologist to the patient and his/her companion. At days 4, $8,15,60$ and 180, the patient was oriented to return to doctor's office for evaluation and photographic follow-up. At day 4, in particular, the composite LSR score was calculated. By the end of treatment we applied a questionnaire to the patient with five questions about his/ her opinion about the treatment performed (Chart).

\section{Ethical aspects}

The present study was approved by the Ethics and Local Research Committee, identified as CAAE 61182716.6.0000.5412. All the procedures performed complied with the standards of Resolution 196/96 of the National Health Council. All individuals were duly informed and agreed with the procedures performed.

\section{Statistical analysis}

All data collection was systematized using Numbers software, version 4.1.1, Apple Inc. Statistical analysis was performed through SPSS (IBM), version 21.0, for Mac OS system. The means and standard deviations of the variables age, composite LSR score and specific scores for face and scalp were calculated. The distribution of this sample did not establish normality. The Spearman 
test evaluated the following correlations: age versus composite LSR score, treated area versus composite LSR score, face versus composite LSR score and scalp versus composite LSR score. To evaluate the risk of LSRs in relation to the use of IM, a generalized Poisson regression model was used with the dependent variable composite LSR score and the covariates age, sex, race, skin type (Fitzpatrick), treated area of the face and treated area of scalp.

\section{RESULTS}

The patients studied had, on average, 68.81 years of age, with a standard deviation of 7.72 , with a minimum of 49 years and a maximum of 85 years; men (51.35\%), skin types II $(64.86 \%)$ and III $(24.30 \%)$, according to Fitzpatrick's classification, were the most common (64.86\%) and the Caucasian race predominated $(97.30 \%)$ with the exception of an Asian man. Almost half of the patients $(48.65 \%)$ had a positive personal history of skin cancer $-89 \%$ of keratinocyte carcinoma and $11 \%$ of malignant melanoma - and most $(54.05 \%)$ had been previously treated for actinic keratosis. The treated areas were nasal (33.82\%), forehead (27.94\%), malar $(23.53 \%)$ and scalp $(14.70 \%)$. In the vast majority $(91.18 \%)$, the number of AKs was greater than five per $25 \mathrm{~cm}^{2}$ skin area. Adherence to a three-day treatment with ingenol mebutate was $100 \%$ and nearly half of these subjects $(40.54 \%)$ decided also to treat sequentially a second, third, fourth or fifth area with IM.

\section{Local Skin Reactions}

The mean $( \pm \mathrm{SD})$ composite LSR score in the 68 treatments was $8.61 \pm 4.22)$. The highest score, individually, was for the item erythema (Graph 1). In second place, in equal percentage, appeared swelling and crusting. The maximum composite score recorded was 19 , which occurred in two treatments and the most severe case is illustrated (Figures 1, 2, 3 and 4). Three cases had a composite LSR score of 2 , the minimum found in this study.

Age did not show a correlation with the composite LSR score (rho $=-0.080, p=0.521)$. There was a correlation between the composite LSR score and the treated area (rho $=-0.371, \mathrm{p}=0.002)$. Subdividing the face (composite LSR score of 9.37 \pm 4.05 ) and scalp (composite LSR score of 4.30 \pm 2.11 ), the correlation between face and composite LSR score was significant ( $r h o=0.501, \mathrm{p}<0.001$ ). In view of the correlation results, the association between variables of interest and the appearance of LSR was analyzed, the scalp being the reference when compared to the facial region. This presented 2.3 times the risk of a LSR (Table 1).

\section{Patients' Perspectives}

Regarding the patients' perspectives about IM treatment, $75.68 \%$ of them considered it great (Q1); discomfort with the treatment (Q2) was reported as reasonable in $40.54 \%$, and $13.51 \%$ of the patients denied any discomfort from the treatment (Chart 1 and Graph 2). Of all ten adverse reactions studied (Q3), erythema and local pruritus, in the same percentage (16\%), were the ones that most disturbed the patients. The report of no adverse reactions was also recorded by five patients (14\%). Almost all patients $(97.30 \%)$ reported improved self-esteem after treatment completion (Q4) (Graph 2). The final score (0-10) referring the treatment (Q5) reported by the patients ranged from 7 to 10 , and 9.4 was the global average.

During this study no serious adverse events were recorded. There was no need for urgent/emergency care and a single case of local acute bacterial infection was diagnosed and promptly treated with oral azithromycin. Self-administration of analgesics (single dose of dipyrone) was performed by three patients due to mild headache. Regarding the need to use other systemic medications, no drug has been prescribed for any reason related to IM treatment.

\section{DISCUSSION}

This study evaluated clinical safety, tolerability, and patients' perspectives regarding the use of ingenol mebutate gel for face and scalp AKs. The results of this study reproduce the findings of the international literature. ${ }^{10}$ The severity of local cutaneous reactions was mild to moderate in most cases (mean composite LSR score was $8.6 \pm 4.2$ ). These results are similar to those obtained in four multicenter randomized controlled trials (mean composite LSR of 9.1 \pm 4.1 ) and in Brazilian individuals (mean composite LSR of $10.8 \pm 3.1) .{ }^{27,30}$ It is important to mention that LSRs occurred in a

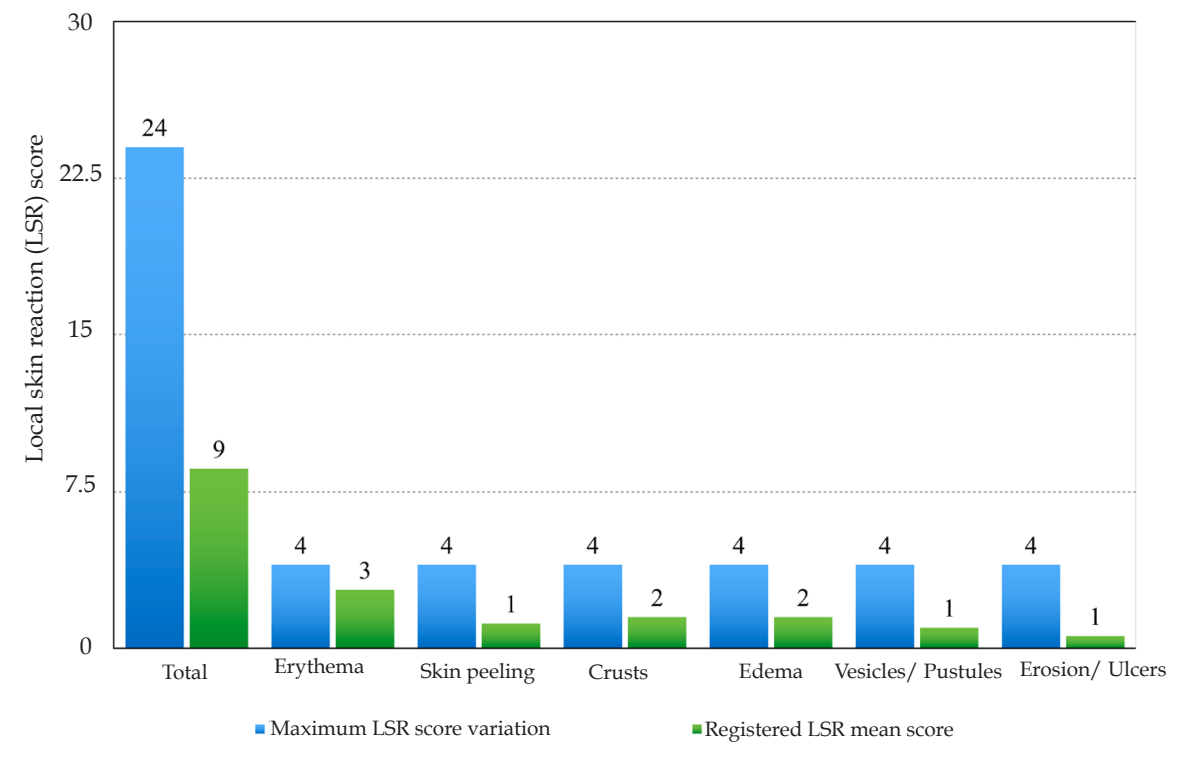

Graph 1: Local Skin Reaction (LSR) Score 


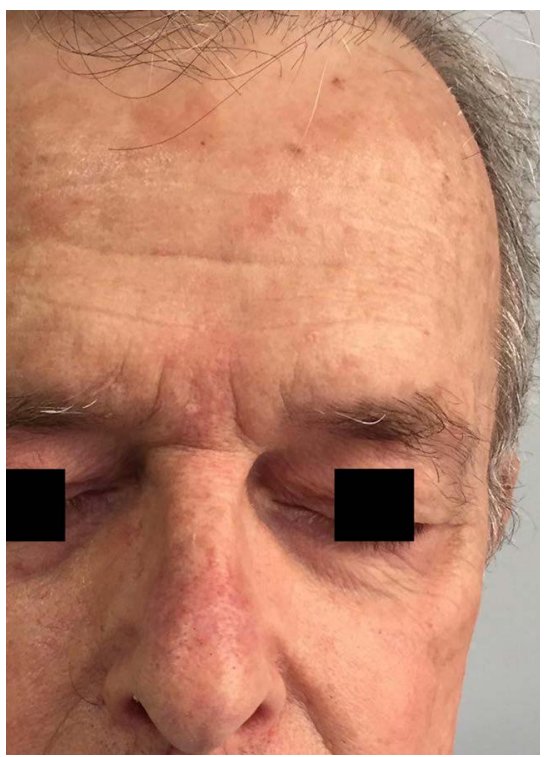

Figure 1: (pre-application/ first day of treatment). Day 1

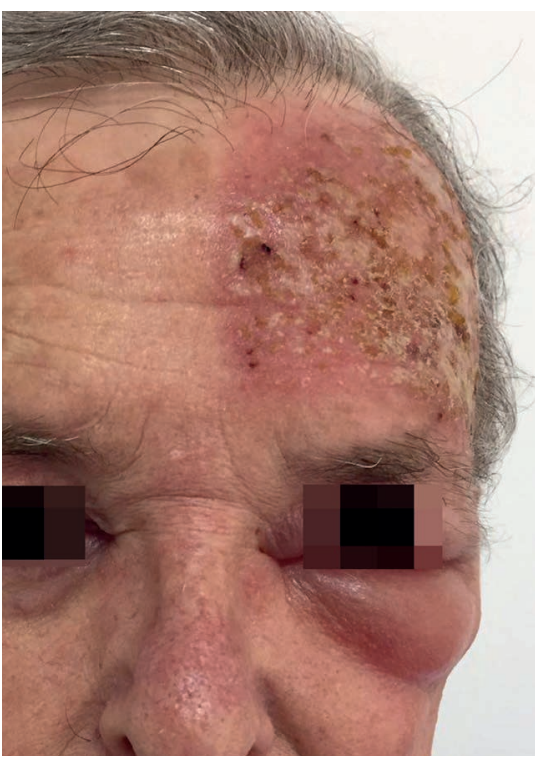

Figure 2

Patient follow-up (severe local skin reaction). Day 4

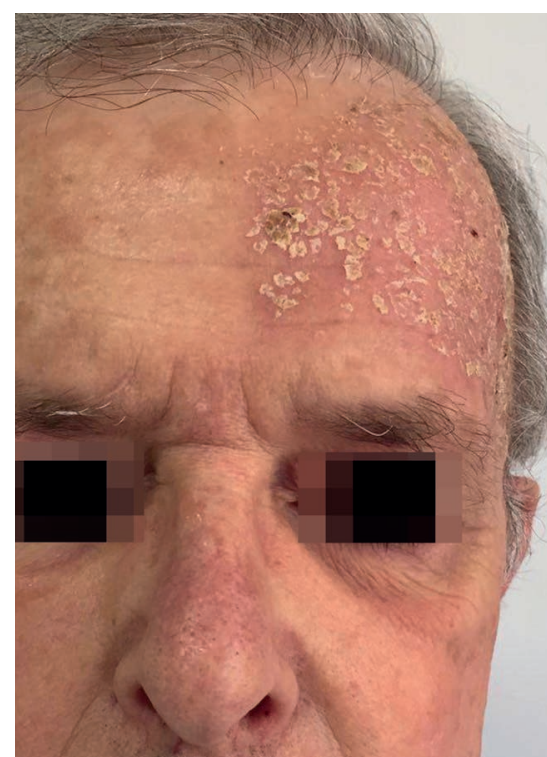

Figure 3:

Patient follow-up

(severe local skin reaction). Day 8

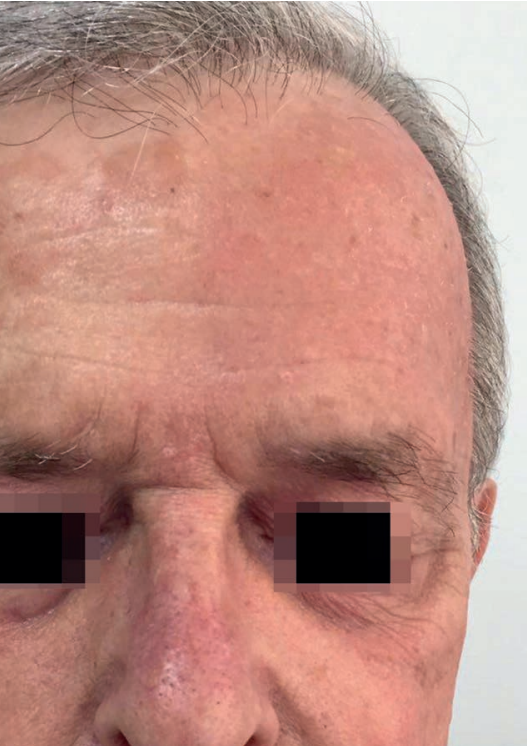

Figure 4:

Patient follow-up (severe local skin reaction). Day 15 very predictable manner, regardless of degree. Both the peak of total score (usually on the third or fourth day of the application) and skin recovery time to baseline (around the 15th day) occurred as observed in previous studies. It is appropriate to emphasize that the risk of LSR was 2.3 times higher in treatments on the face than on the scalp. This finding may be useful in the therapeutic decision of which area to address first, both regarding the aesthetic discomfort and the uncertainties related with the use of a new drug.

AK prevalence increases with aging. No difference in safety profile in distinct age groups occurred in initial analyses for ingenol mebutate approval. ${ }^{10,31}$ Subsequent studies have corroborated these data, even in investigations involving populations with a mean age of 72 and 74.5 years. ${ }^{32,33}$ In our study as well, no correlation between age (mean of 68.81 years) and composite LSR score was observed and discomfort caused by treatment reactions was reported as mild to moderate by $71 \%$ of patients; $14 \%$ of the sample reported no discomfort at all. The fact that adherence to treatment was $100 \%$ and 98\% of patients answered (Q1) that the treatment with the ingenol gel was great or good leads us to presume that although the LSRs are significant, they are tolerable and transient and success is achieved. The improvement in self-esteem (Q4) occurred in 97\% of patients and demonstrates the visible secondary benefit of this drug, which has not been yet thoroughly studied, in the attenuation of photoaging. ${ }^{34}$ This is also confirmed by the fact that almost half the patients ( $41 \%$ ) decided to treat in sequence a second, third, fourth or fifth area with IM, as observed in our study.

Regarding the systemic absorption of ingenol mebutate, two phase 1 (NCT00659893) and phase 2 (NCT00852137) safety studies have analyzed, respectively, dose escalation and pharmacokinetic evaluation, after application of the gel at $0.05 \%$, for two 
consecutive days on an area of $100 \mathrm{~cm}^{2}$ of the forearm. ${ }^{35}$ As a result of this research, there was no systemic absorption of ingenol mebutate (and its two metabolites) and a good tolerability profile was observed at a concentration four times higher that recommended in clinical studies. ${ }^{35,36}$ This evidence supports the safe use of this drug even in patients in advanced age, with multiple comorbidities and under the use of numerous medications. In our study, involving a

\begin{tabular}{|c|c|c|c|c|c|}
\hline Variable & B & $\mathrm{df}$ & RR & $95 \%$ CI & $p^{*}$ \\
\hline (source order) & 1.684 & 1 & 5.390 & $2.04-14.19$ & 0.001 \\
\hline Age & -0.005 & 1 & 0.995 & $0.98-1.01$ & 0.386 \\
\hline Sex & -0.177 & 1 & 0.838 & $0.70-1.00$ & 0.051 \\
\hline Race & 0.347 & 1 & 1.414 & $0.76-2.64$ & 0.276 \\
\hline Fitzpatrick & -0.019 & 1 & 0.981 & $0.85-1.13$ & 0.796 \\
\hline Face area & 0.844 & 1 & 2.325 & $1.68-3.21$ & 0.000 \\
\hline Scalp area & 0 & 1 & 1 & - & - \\
\hline
\end{tabular}

Note: *generalized Poisson regression model was used with the dependent variable composite LSR score. B: beta coefficients; dF: degrees of freedom; RR: Relative Risk; 95\% CI: 95\% confidence interval.

Q1 - What is your opinion regarding treatment with IM?

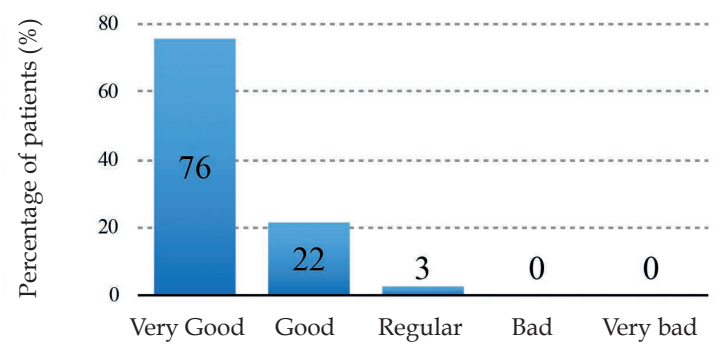

Q3 - What was the most uncomfortable adverse reaction due to the treatment with IM?

20

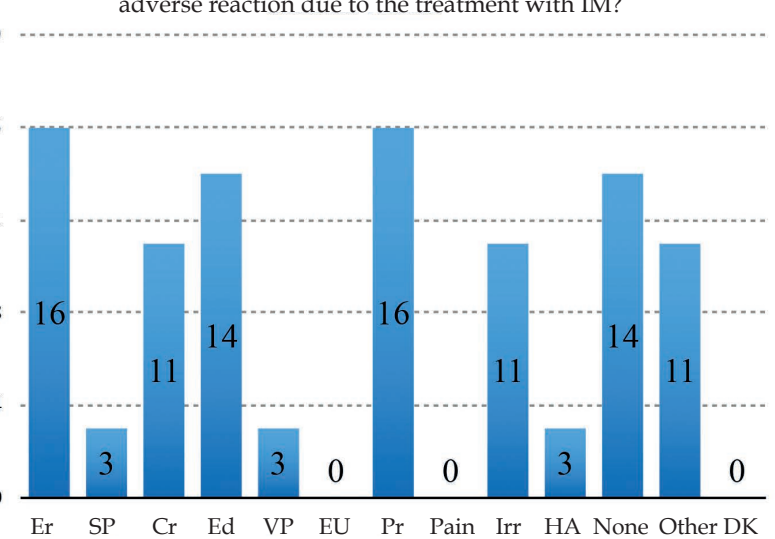

Erythema, Skin peeling, Crusts, Edema, Vesicles/ Pustules, Erosion/

Ulcers, Local pruritus, Local pain, Irritation, Headache, None, Other, Do not know
CHART 1: Questionnaire to evaluate patients' perspectives related to treatment with ingenol mebutate

1. What is your opinion about the treatment? optimum () good () regular () bad () very bad ()

2. How much was the discomfort caused by the treatment reactions?

none () slight () reasonable () intense ()

3. What was the most troublesome adverse reation to treatment?

erythema( ) scales( ) crusting( ) swelling( ) vesiculation/pustulation( ) erosion/ulceration( ) pruritus( ) local pain( ) irritation( ) headache( ) none( ) other( ) unknown( )

4. What do you think of your self-steem after treatment? improved () did not change () got worse ()

5. What score (from zero to ten) would you give for the treatment?

Q2 - How much was the discomfort caused by the treatment reactions?

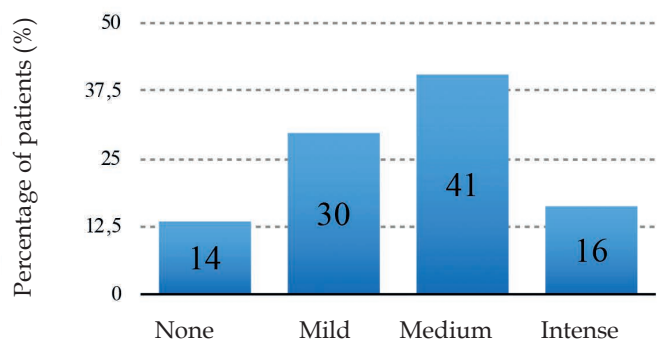

Q4 - What do you think of your self-esteem after the treatment with IM?

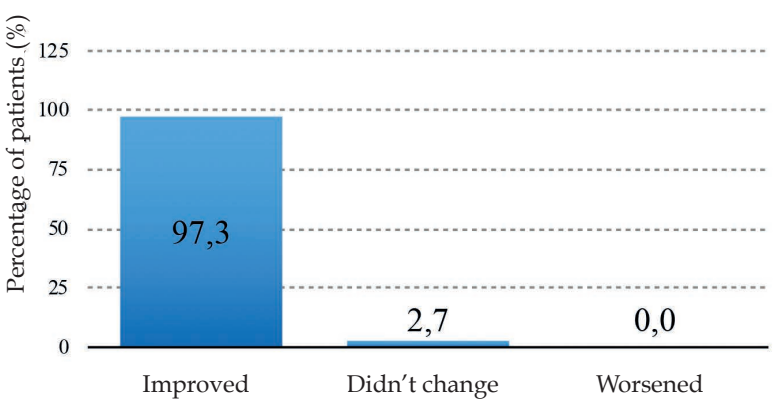

Graph 2: Patients' perspectives. Answers obtained by the questionnaire at the end of treatment. 
group of 37 patients who underwent treatment of almost 70 areas with MI, no systemic event or need for other medical care was recorded.

Like any chronic illness, adherence to long-term treatment is often a problem. Although several therapeutic options are available to treat AKs, both the direct approach of the lesions and the management of cancerization field are, in clinical practice, a challenge. In general, all approved modalities for this disease, pharmacological or not, involve some degree of discomfort, itching or pain for the patient. In addition, they often cause local reactions ranging from erythema, crusts, blistering, and even skin erosion. Occasionally, even systemic reactions can occur with the use of imiquimod, for example. Notwithstanding such drawbacks, the duration of treatment is usually long, ranging from weeks to months. Furthermore, from a psychological point of view for the patient, an aggravating factor is that most of the lesions involve the face, an area of great aesthetic relevance. Thus, abrupt changes in appearance, may significantly affect social and professional routine of these individuals. Finally, it is extremely important to address the cost issue concerning different available field-directed therapies. This consideration, in our view, needs to be quite critical. The complete cycle of treatment and the significant possibility of non-adherence should be valued. It occurs in more than half of the patients 3 to 4 weeks after the start of the medication and reaches almost $70 \%$ in treatments of 4 to 8 weeks. ${ }^{20,37}$ Treatment duration and its adverse effects are considered the most preponderant predictive factors of non-adherence. ${ }^{20,37}$ Therefore, when considering the efficacy of a drug, which was established in randomized clinical trials (RCTs), one should also estimate the real risk of non-adherence in longer modalities. ${ }^{20,38}$ As a result of this, clinical follow-up studies are also necessary in the post-marketing phase. ${ }^{39}$ Due to the fact that ingenol mebutate has a two or three consecutive-day regimen, patient adherence rates are often close to a $100 \%$ (as observed in our study). ${ }^{27}$ The efficacy of IM in clinical practice ("real world") has been shown to be equivalent to that established in RCTs. ${ }^{27,40}$ Recently, an international consensus of eight US, Brazilian, European and Australian AK expert dermatologists has concluded that shorter and better-managed treatments have the potential to substantially increase effectiveness in the real world. ${ }^{41}$

There were limitations in our research. Local skin reaction score varies over time, from zero to peak and return to baseline. The ideal would be a daily patient follow-up to determine the maximum composite LSR score more precisely. The questionnaire to evaluate the patient's opinion after the end of the treatment was made by phone by the researcher himself. Perhaps, this result could be different if applied by someone else. The study covered more than one area treated in several patients. In the majority of patients, the treated area had more than $10 \mathrm{AK}$ lesions per $25 \mathrm{~cm}^{2}$ field. The degree of perception of improvement by the patient could eventually differ if there were fewer lesions per field. Slightly more than a third of the patients had not previously been treated for AK, which limited the comparison parameter between IM and other therapeutic modalities.

In our study, five factors, perceived during direct contact with patients, were predictors of successful management of face and scalp AKs with ingenol mebutate: (i) short-term treatment with rapid and predictable recovery of the skin after the LSRs; (ii) trust in the physician and his/her availability in the attendance of any doubts or events that arose during the reactions; (iii) application of the gel by the dermatologist in the office, and in the presence of a patient's companion, at least on the first day; (iv) clear and assertive patient information about AK (chronic character, ultraviolet radiation, risk of malignization, cancerization field, different modalities of approach, LSRs, costs) and (v) alignment of patient expectations regarding use of IM.

Future studies could prove, in prospective studies, whether the treatment of cancerization field effectively reduces the incidence of SCC and its associated morbidity and mortality. The possibility of treating areas larger than $25 \mathrm{~cm}^{2}$ with IM would be very useful in the clinical setting. Additionally, further investigation of the effect of IM on cutaneous photoaging would be quite interesting, since the improvement of skin appearance is commonly observed and reported by treated patients.

\section{CONCLUSION}

The treatment of face and scalp AKs with $0.015 \%$ ingenol mebutate gel was considered safe and tolerable in Brazilian subjects. The perspective, from the patients' point of view, was positive, with a high rate of adherence to treatment and a great improvement in self-esteem. $\square$

\section{REFERENCES}

1. Einspahr JG, Stratton SP, Bowden GT, Alberts DS. Chemoprevention of human skin cancer. Crit Rev Oncol Hematol. 2002;41:269-85.

2. Vatve M, Ortonne JP, Birch-Machin MA, Gupta G. Management of field change in actinic keratosis. . Br J Dermatol. 2007;157(Suppl 2):21-4.

3. Schmitt JV, Miot HA. Queratoses actínicas: revisão clínica e epidemiológica. An Bras Dermatol. 2012;87:425-34.

4. Landis ET, Davis SA, Taheri A, Feldman SR. Top dermatologic diagnoses by age. Dermatol Online J. 2014;20:22368.

5. Sociedade Brasileira de Dermatologia. Nosologic profile of dermatologic visits in Brazil. An Bras Dermatol. 2006;81:549-58.
6. Frost CA, Green AC. Epidemiology of solar keratoses. $\mathrm{Br} \mathrm{J}$ Dermatol. 1994;131:455-64.

7. Berman B, Goldenberg G, Hanke CW, Tyring SK, Werschler WP, Knudsen KM, et al. Efficacy and safety of ingenol mebutate $0.015 \%$ gel 3 weeks after cryosurgery of actinic keratosis: 11-week results. J Drugs Dermatol. 2014;13:154-60.

8. Ishioka P, Marques SA, Hirai AT, Marques ME, Hirata SH, Yamada S. Prevalence of precancerous skin lesions and non-melanoma skin cancer in Japanese-Brazilians in Bauru, São Paulo State, Brazil. Cad Saude Publica. 2009;25:965-71.

9. Berman B. New developments in the treatment of actinic keratosis: focus on ingenol mebutate gel. Clin Cosmet Investig Dermatol. 2012;5:111-22. 
10. Berman B. Safety and tolerability of ingenol mebutate in the treatment of actinic keratosis. Expert Opin Drug Saf. 2015;14:1969-78

11. Criscione VD, Weinstock MA, Naylor MF, Luque C, Eide MJ, Bingham SF, et al. Actinic Keratoses. Natural history and risk of malignant transformation in the Veterans Affairs Topical Tretinoin Chemoprevention Trial. Cancer. 2009;115:2523-30.

12. Dodson JM, DeSpain J, Hewett JE, Clark DP. Malignant potential of actinic keratoses and the controversy over treatment. A patient-oriented perspective. Arch Dermatol. 1991;127:1029-31.

13. Marks R, Rennie G, Selwood TS. Malignant transformation of solar keratoses to squamous cell carcinoma. Lancet. 1988;1:795-7.

14. de Berker D, McGregor JM, Mohd Mustapa MF, Exton LS, Hughes BR. British Association of Dermatologists' guidelines for the care of patients with actinic keratosis 2017. Br J Dermatol. 2017;176:20-43.

15. Tzogani K, Nagercoil N, Hemmings RJ, Samir B, Gardette J, Demolis P,et al. The European Medicines Agency approval of ingenol mebutate (Picato) for the cutaneous treatment of non-hyperkeratotic, non-hypertrophic actinic keratosis in adults: summary of the scientific assessment of the Committee for Medicinal Products for Human Use (CHMP). Eur J Dermatol. 2014;24:457-63.

16. Abdalla B, Rstom SA, Paschoal FM. Field cancerization: a review article. Surg Cosmet Dermatol. 2014;6:310ᄀ-8.

17. Stockfleth $\mathrm{E}$. The paradigm shift in treating actinic keratosis: A comprehensive strategyJ Drugs Dermatol. 2012;11:1462-7.

18. Torezan LA, Festa-Neto C. Campo de cancerização cutâneo: implicações clínicas, histopatológicas e terapêuticas. An Bras Dermatol. 2013;88:775-86.

19. Werner RN, Stockfleth E, Connolly SM, Correia O, Erdmann R, Foley P, et al. Evidence-and consensus-based (S3) Guidelines for the Treatment of Actinic Keratosis - International League of Dermatological Societies in cooperation with the European Dermatology Forum - Short versionJ Eur Acad Dermatol Venereol. 2015;29:2069-79.

20. Peris K, Calzavara-Pinton PG, Neri L, Girolomoni G, Malara G, Parodi A, et al. Italian expert consensus for the management of actinic keratosis in immunocompetent patients. J Eur Acad Dermatol Venereol. 2016;30:1077-84.

21. Hofbauer G, Anliker M, Boehncke WH, Brand C, Braun R, Gaide 0 et al. Swiss clinical practice guidelines on field cancerization of the skin. Swiss Med Wkly. 2014;144:w14026.

22. Consultas.anvisa.gov.br [Internet]. Agência Nacional de Vigilância Sanitária (ANVISA). Consulta de produtos/ medicamentos [acesso 26 Nov 2017]. Disponivel em: https://consultas.anvisa.gov.br/\#/medicamentos/ $\mathrm{q} /$ ?numeroRegistro $=185690005$.

23. Rosen RH, Gupta AK, Tyring SK. Dual mechanism of action of ingenol mebutate gel for topical treatment of actinic keratoses: Rapid lesion necrosis followed by lesion-specific immune response. J Am Acad Dermatol. 2012;66:486-93.

24. Ogbourne SM, Suhrbier A, Jones B, Cozzi SJ, Boyle GM, Morris M, et al. Antitumor activity of 3-ingenyl angelate: plasma membrane and mitochondrial disruption and necrotic cell death. Cancer Res. 2004;64:2833-9.

25. Stahlhut M, Bertelsen M, Hoyer-Hansen M, Svendsen N, Eriksson AH, Lord JM, et al. Ingenol mebutate: induced cell death patterns in normal and cancer epithelial cells. J Drugs Dermatol. 2012;11:1181-92.
26. Hampson P, Kavanagh D, Smith E, Wang K, Lord JM, Ed Rainger G. The antitumor agent, ingenol-3-angelate (PEP005), promotes the recruitment of cytotoxic neutrophils by activation of vascular endothelial cells in a PKC-delta dependent manner. Cancer Immunol Immunother. 2008;57:1241-51.

27. Lebwohl M, Swanson N, Anderson LL, Melgaard A, Xu Z, Berman B. Ingenol mebutate gel for actinic keratosis. N Engl J Med. 2012;366:1010-9.

28. Lebwohl M, Shumack S, Stein Gold L, Melgaard A, Larsson T, Tyring SK. Longterm follow-up study of ingenol mebutate gel for the treatment of actinic keratoses. JAMA Dermatol. 2013;149:666-70.

29. Garbe C, Basset-Seguin N, Poulin Y, Larsson T, Østerdal ML, Venkata R, et al. Efficacy and safety of follow-up field treatment of actinic keratosis with ingenol mebutate $0.015 \%$ gel: a randomized, controlled 12 -month study. $\mathrm{Br} J$ Dermatol. 2016;174:505-13.

30. Samorano LP, Torezan LA, Sanches JA. Evaluation of the tolerability and safety of a $0.015 \%$ ingenol mebutate gel compared to $5 \% 5$-fluorouracil cream for the treatment of facial actinic keratosis: a prospective randomized trial. J Eur Acad Dermatol Venereol. 2015;29:1822-7.

31. Ema.europa.eu [Internet]. European Medicines Agency. Product information. Picato: $E M E A / H / C / 002275-R / 0023$ [cited 2017 Nov 26]. Available from: http://www.ema.europa.eu/ema/index.jsp?curl=pages/medicines/human/ medicines/002275/human_med_001600.jsp\&mid=WC0b01ac058001d124.

32. Garbe C, Basset-Seguin N, Poulin Y, Larsson T, Knudsen KM, Lear J. Safety of follow-up field application of ingenol mebutate $0.015 \%$ gel for actinic keratoses on face and scalp. J Am Acad Dermatol. 2015;72(Suppl 1): AB191.

33. Pellacani G, Peris K, Guillen C, Clonier F, Larsson T, Venkata R, et al. A randomized trial comparing simultaneous versus sequential field treatment of actinic keratosis with ingenol mebutate on two separate areas of the head and body. J Eur Acad Dermatol Venereol. 2015;29:2192-8.

34. Braun SA, Gerber PA. Cosmetic effects of ingenol mebutate gel in the treatment of field-cancerized photodamaged skin. Dermatol Surg. 2015;41:1328-9.

35. Anderson L, Jarratt M, Schmieder G, Shumack S, Katsamas J, Welburn P. Tolerability and pharmacokinetics of ingenol mebutate $0.05 \%$ gel applied to treatment areas up to $100 \mathrm{~cm} 2$ on the forearm(s) of patients with actinic keratosis. J Clin Aesthet Dermatol. 2014;7:19-29.

36. Leo-pharma.com.br [Internet]. LEO Pharma Ltda. PICATO®gel. Bula aprovada pela ANVISA (09/06/2015) [acesso 29 Nov 2017]. Disponível em: http://www. leo-pharma.com.br/Files/Filer/Picato.pdf.

37. Shergill B, Zokaie S, Carr AJ. Non-adherence to topical treatments for actinic keratosis. Patient Prefer Adherence. 2013;8:35-41.

38. Gwadry-Sridhar FH, Manias E, Lal L, Salas M, Hughes DA, Ratzki-Leewing A, et al. Impact of interventions on medication adherence and blood pressure control in patients with essential hypertension: a systematic review by the ISPOR medication adherence and persistence special interest group. Value Health. 2013;16:863-71.

39. Sherman RE, Anderson SA, Dal Pan GJ, Gray GW, Gross T, Hunter NL, et al. Realworld evidence - what is it and what can it tell us? N Engl J Med. 2016;375:2293-7.

40. Ricci F, Tambone S, Neri L, Fania L, Piccioni A, Guerriero C, et al. Real-life efficacy and safety of ingenol mebutate for the treatment of actinic keratosis of the face and scalp: A single arm retrospective study. J Dermatolog Treat. 2016;27:525-530.

41. Stockfleth E, Peris K, Guillen C, Cerio R, Basset-Seguin N, Foley P, et al. A consensus approach to improving patient adherence and persistence with topical treatment for actinic keratosis. Int J Dermatol. 2015;54:509-15.

\section{AUTHORS'CONTRIBUTIONS}

Luiz Gameiro

(iD) ORCID

0000-0003-2874-6771

Approval of the final version of the manuscript, Conception and planning of the study, Elaboration and writing of the manuscript, Obtaining, analyzing and interpreting the data, Intellectual participation in propaedeutic and/or therapeutic conduct of the cases studied, Critical review of the literature, Critical review of the manuscript

Luis Fernando Requejo Tovo

(iD) ORCID $0000-0001-5327-883 x$

Approval of the final version of the manuscript, Conception and planning of the study

José Antonio Sanches Júnior $\quad$ (iD) ORCID 0000-0002-5709-092X

Approval of the final version of the manuscript, Conception and planning of the study, Effective participation in research orientation, Critical review of the manuscript

Ivan Aprahamian

(iD) ORCID

0000-0003-3806-7895

Statistical analysis, Approval of the final version of the manuscript, Conception and planning of the study, Effective participation in research orientation, Intellectual participation in propaedeutic and/or therapeutic conduct of the cases studied, Critical review of the manuscript

How to cite this article: Gameiro L, Tovo LFR, Sanches JA, Aprahamian I. Treatment of actinic keratoses and cancerization field of the face and scalp with $0.015 \%$ ingenol mebutate gel in Brazilian individuals: safety, tolerability and patients' perspectives. An Bras Dermatol. 2019;94(3):313-9. 